\title{
Effect of Plant Age, Temperature, and Vector Load on 'Candidatus Liberibacter solanacearum' in Planta Titer and Shoot Proliferation Symptoms in Carrot
}

\author{
Atalya Keshet-Sitton, ${ }^{1}$ Alon Piasezky, ${ }^{1,2}$ Nofar Assoline, ${ }^{1,2}$ Orit Dror,${ }^{1}$ and Ofir Bahar ${ }^{1, \dagger}$ \\ ${ }^{1}$ Department of Plant Pathology and Weed Research, Agricultural Research Organization, Volcani Institute, Rishon LeZion, Israel \\ ${ }^{2}$ The Robert H. Smith Faculty of Agriculture, Food and Environment, The Hebrew University of Jerusalem, Rehovot, Israel \\ Accepted for publication 16 July 2021.
}

\begin{abstract}
A decade ago, shoot proliferation symptoms (i.e., witches' broom) in carrots were believed to be the cause of 'Candidatus Phytoplasma' and Spiroplasma infection, yet in recent years this association appeared to have weakened, and a closer association was found with the yetunculturable, psyllid-transmitted Gram-negative bacterium 'Candidatus Liberibacter solanacearum'. In Israel, carrots are grown throughout the year, yet shoot proliferation symptoms tend to appear only in mature plants and mostly in late spring to early summer. We hypothesized that factors such as plant age, temperature, and vector load, which vary during the year, have a critical effect on symptom development and examined these factors under controlled conditions. Here we show that young carrot seedlings are as prone as older plants to develop shoot proliferation symptoms after ' $\mathrm{Ca}$. L. solanacearum' inoculation. Surprisingly, we found that the local ' $\mathrm{Ca}$. L. solanacearum' haplotype was extremely
\end{abstract}

ABSTRACT sensitive to constant temperature of $30^{\circ} \mathrm{C}$, which led to a significant reduction in bacterial growth and symptom development compared with $18^{\circ} \mathrm{C}$, which was very conducive to symptom development. We have also found that inoculations with 10 or 20 psyllids per plant results in faster symptom development compared with inoculations with two psyllids per plant; however, the difference between vector loads in disease progress rate was not significant. These data provide important insights to the effects of plant age, growth temperature, and vector load on ' $\mathrm{Ca}$. L. solanacearum' and its associated symptoms and further strengthen the notion that ' $\mathrm{Ca}$. L. solanacearum' is the main responsible agent for carrot witches' broom in Israel.

Keywords: bacterial pathogens, 'Candidatus Liberibacter solanacearum', carrot, shoot proliferation, witches broom
'Candidatus Liberibacter solanacearum', belonging to the larger genus ' $C a$. Liberibacter', is a vector-transmitted, yet-unculturable alpha-proteobacterium associated with plant disorders in two main families, Solanaceae and Apiaceae (Hansen et al. 2008; Liefting et al. 2008; Munyaneza et al. 2010). Multiple genetic variants of ' $\mathrm{Ca}$. L. solanacearum' (called haplotypes) have been established thus far, having different hosts, insect vectors, and geographic preferences. Haplotype determination is based on single nucleotide polymorphism and on nucleotide insertion and deletion in the ribosomal RNA region (Nelson et al. 2011, 2013a; Teresani et al. 2014). 'Ca. L. solanacearum' haplotypes A and B are associated with disorders mainly in potato (zebra chip) and tomato (Liefting et al. 2008; Munyaneza et al. 2007; Nelson et al. 2011), and haplotypes C, D, and E were found in association with disorders in plants from the Apiaceae family, mainly carrot and celery (Alfaro-Fernandez et al. 2012a; Munyaneza et al. 2012b; Nelson et al. 2013a; Teresani et al. 2014). Additional haplotypes, U, F, $\mathrm{G}$, and $\mathrm{H}$, which are thus far less characterized in terms of their agricultural impact, were recently identified (Haapalainen et al. 2018, 2019; Mauck et al. 2019; Swisher Grimm and Garczynski 2019).

Among the three main ' $\mathrm{Ca}$. L. solanacearum' haplotypes infecting carrots, a clear geographic separation appears. Haplotype $\mathrm{C}$ has

\section{${ }^{\dagger}$ Corresponding author: O. Bahar; ofirb@agri.gov.il}

Funding: This study was financially supported by the European Union Horizon 2020 Research and Innovation Programme under grant agreement 635646 (Pest Organisms Threatening Europe).

*The $\boldsymbol{e}$-Xtra logo stands for "electronic extra" and indicates that three supplementary figures are published online.

The author(s) declare no conflict of interest. been found solely in northern European countries (Haapalainen et al. 2016; Munyaneza et al. 2012b, 2014, 2015), and haplotypes D and $\mathrm{E}$ were found in southern Europe and around the Mediterranean basin (Alfaro-Fernández et al. 2012a; Ben Othmen et al. 2018; Hajri et al. 2017; Mawassi et al. 2018; Nelson et al. 2013a; Tahzima et al. 2014). Interestingly, the insect vectors transmitting ' $C a$. L. solanacearum' to carrot plants are also geographically separated. The psyllid Trioza aplicalis Förster is the primary vector of 'Ca. L. solanacearum' in northern Europe (Munyaneza et al. 2010; Nissinen et al. 2014), and Bactericera trigonica Hodkinson transmits 'Ca. L. solanacearum' around the Mediterranean basin (Alfaro-Fernandez et al. 2012a; Mawassi et al. 2018; Tahzima et al. 2017). It is not yet clear whether the geographic separation of the $\mathrm{C}$ versus the $\mathrm{D}$ and $\mathrm{E}$ haplotypes is driven by the geographic separation of the insect vector or by other factors such as climate or environmental conditions.

Intriguingly, despite infecting the same host plant, different haplotypes of ' $\mathrm{Ca}$. L. solanacearum' are associated with different disease symptoms in carrot. For example, the symptom most clearly associated with ' $\mathrm{Ca}$. L. solanacearum' haplotypes D and $\mathrm{E}$ is shoot proliferation or witches' broom (Alfaro-Fernandez et al. 2012a; Ben Othmen et al. 2018; Loiseau et al. 2014; Mawassi et al. 2018; Tahzima et al. 2014). On the other hand, ' $C a$. L. solanacearum' haplotype $\mathrm{C}$ is associated primarily with leaf discoloration and stunted growth and does not induce shoot proliferation (Munyaneza et al. 2012b, 2015; Nissinen et al. 2014). Witches' broom symptoms in carrots were also associated with ' $\mathrm{Ca}$. Phytoplasma', another vector-transmitted, yet-unculturable bacterium (Orenstein et al. 1999). However, this association seems to have weakened significantly in Israel, as a recent survey revealed that witches' broom symptoms are associated primarily with ' $\mathrm{Ca}$. Liberibacter solanacearum' and not with ' $\mathrm{Ca}$. Phytoplasma' (Mawassi et al. 2018). 
In Israel, although carrots are grown throughout the year, symptoms associated with ' $\mathrm{Ca}$. L. solanacearum' haplotype D tend to appear only during late spring to summer. For example, carrots sown in September and October and harvested in February (late winter) are less likely to have shoot proliferation symptoms. On the other hand, carrot sown in late December and harvested in late May or June (beginning of summer) would probably have a high degree of shoot proliferation symptoms. Nevertheless, when carrots are sown in the "susceptible" months (December and January), symptoms mostly appear close to harvest and not in the early stages of growth. The lack of symptoms in these early stages cannot be explained by the absence of the psyllid vector, because psyllids were shown to be prevalent and to carry ' $\mathrm{Ca}$. L. solanacearum' during the early stages of seedling emergence (Mawassi et al. 2018). These observations raise several questions related to the environmental and physiological factors that may affect ' $C a$. L. solanacearum'-induced shoot proliferation symptom development in carrot. For example, what is the effect of temperature and of the physiological age of the plants on their susceptibility to ' $\mathrm{Ca}$. L. solanacearum'-associated symptoms?

Indeed, environmental factors may have a great effect on the development of plant diseases. Experiments with ' $\mathrm{Ca}$. L. asiaticus', the huanglongbing (HLB) disease agent, have shown that within the complex of ' $C a$. L.' species infecting citrus, ' $C a$. L. asiaticus' is heat tolerant and ' $\mathrm{Ca}$. L. africanus' and ' $\mathrm{Ca}$. L. americanus' are heat sensitive (Bové 2006; Lopes et al. 2009). In these experiments, heat sensitivity, manifested as slower bacterial growth rate or lack of disease symptom development, was observed in temperatures $>27^{\circ} \mathrm{C}$. It was speculated that this important characteristic is one of the main factors determining the world distribution of HLBassociated species (Nelson et al. 2013b). Experiments were also conducted with ' $\mathrm{Ca}$. L. solanacearum' in potato (haplotype not determined, A, B, or mixed), showing that low temperatures $\left(<17^{\circ} \mathrm{C}\right)$ suppress disease development and temperatures $>32^{\circ} \mathrm{C}$ prevent bacterial multiplication in the plant and disease symptom appearance (Munyaneza et al. 2012a). To the best of our knowledge, the effect of various incubation temperatures on ' $\mathrm{Ca}$. L. solanacearum' haplotypes infecting carrot has thus far not been directly evaluated. Nevertheless, a recent field study from Finland, which evaluated ' $\mathrm{Ca}$. L. solanacearum' haplotype $\mathrm{C}$ titer and associated disease symptoms in carrots in two subsequent years, suggested that seasonal temperatures had a significant effect on both parameters (Nissinen et al. 2021).

Similarly to environmental conditions, the physiological age of plants during inoculation and infection could have a critical effect on disease development and symptom appearance (Chang et al. 1992; Kus et al. 2002). Rashed et al. (2014) reported that the incubation period of ' $\mathrm{Ca}$. L. solanacearum' in potato plants was not significantly affected by the physiological age of the plants during infestation. These results suggested that plants of different ages are similarly susceptible to zebra chip foliar symptoms. Nevertheless, significant effects were noted in yield, where plants inoculated at a younger age had a more substantial decrease in tuber mass at harvest.

Vector load is also a critical factor in disease development and progress. Logically, exposure to a higher number of vectors will result in more feeding events that will lead to more successful transmission events of pathogen cells into the host. Rashed et al. (2012) showed that vector load (one vs. four B. cockerelli adults per plant) affected ' $\mathrm{Ca}$. L. solanacearum' titer at the site of inoculation 3 days after inoculation. However, disease progress rate appeared to be independent of the initial vector load. Buchman et al. (2011) showed that inoculation of potato plants with one $B$. cockerelli psyllid resulted in a lower disease incidence compared with 20 psyllids per plant, when the inoculation access period (IAP) was $24 \mathrm{~h}$ or shorter. When the IAP was $72 \mathrm{~h}$, differences were less pronounced (100 vs. 78\% disease incidence for 20 and one psyllid, respectively). Studies with $B$. trigonica and ' $C a$. L. solanacearum' have shown that longer IAPs are positively correlated with ' $\mathrm{Ca}$. L. solanacearum' transmission (Antolínez et al. 2017; Teresani et al. 2017). Different psyllid loads were used in these studies; however, the correlation between vector load versus ' $\mathrm{Ca}$. L. solanacearum' in planta titer and disease symptom development over time has not been clearly defined, and the authors concluded that this relationship should be studied further (Antolínez et al. 2017).

In the current study we examined the effects of plant age, growth temperature, and vector load on the development of shoot proliferation symptoms in carrot, associated with ' $\mathrm{Ca}$. L. solanacearum' haplotype $\mathrm{D}$, the predominant haplotype in Israel (Mawassi et al. 2018). To address these goals, we conducted experiments under controlled conditions and tested the effect of these variables on symptom development. Additionally, to better understand the relationship between ' $\mathrm{Ca}$. L. solanacearum' and its attributed symptoms in carrots, we estimated the effect of temperature and vector load on ' $\mathrm{Ca}$. L. solanacearum' titers in planta and the correlation between ' $\mathrm{Ca}$. L. solanacearum' titers and disease symptom development.

\section{MATERIALS AND METHODS}

Plant material and growth conditions. Daucus carota (carrot, cultivar Nairobi) seeds were obtained from Eden Seeds Ltd. Carrot seeds were sown in 0.6-liter pots containing perlite (Agrekal Industries, Israel), supplemented daily with NPK (20:20:20) fertilizer via drip irrigation. Plants were grown in a temperature-controlled chamber under natural light conditions.

$B$. trigonica colony origin, maintenance, and plant inoculation. Adults of the carrot psyllid B. trigonica, the insect vector of ' $C a$. L. solanacearum' haplotype D in Israel, were collected from commercial carrot fields via the sweep net technique and released inside BugDorm insect rearing cages $(32.5 \times 32.5 \times 77.0 \mathrm{~cm})$ containing ' $\mathrm{Ca}$. L. solanacearum' haplotype D-infected carrot plants as previously described (Mawassi et al. 2018). Insect cages were placed in a temperature-controlled chamber $\left(22\right.$ to $\left.25^{\circ} \mathrm{C}\right)$ under natural light conditions. Reared psyllids were examined occasionally for ' $\mathrm{Ca}$. L. solanacearum' infection as described below and in Mawassi et al. (2018).

We inoculated the carrot plants used for the various experiments individually by attaching a small rearing mesh bag $(10 \times 15 \mathrm{~cm})$, containing $10 \mathrm{~B}$. trigonica adults (collected from an insect-rearing cage with ' $\mathrm{Ca}$. L. solanacearum'-positive plants), to a single fully developed leaf. IAP was 3 to 7 days, after which psyllids were manually removed and an insecticide (Milbeknock $0.2 \%$ or Confidor $0.15 \%$ ) was applied to prevent development of further generations. Disease symptom development was monitored by observing the emergence of new side shoots (i.e., shoot proliferation, witches' broom; Fig. 1), a typical symptom of ' $\mathrm{Ca}$. L. solanacearum' haplotype D in carrots (Mawassi et al. 2018). Plants were scored as symptomatic with the first appearance of new side shoots.

Total DNA extraction and real-time quantitative PCR analyses. DNA was extracted from carrot plant tissue as described in Mawassi et al. (2018). Real-time quantitative PCR (qPCR) was used to determine the presence of ' $\mathrm{Ca}$. L. solanacearum' or to estimate ' $C a$. L. solanacearum' titer in planta via either the SYBR Green or TaqMan method. The RecA (CKC_05085 F/R) primer set (Ibanez et al. 2014) was used with the SYBR Green method, and the LsoF and HLBr primer set and the HLBp probe (Li et al. 2006, 2009) were used with the TaqMan method. For quantitative assessment of ' $C a$. L. solanacearum' titer in planta we used the RecA primers described previously and the DcACTIN primer set (Tian et al. 2015) of the carrot actin as a normalizing gene. To determine the presence of ' $\mathrm{Ca}$. L. solanacearum' (positive or negative) we used the TaqMan method with the previously mentioned primers. qPCR was performed with $20 \mathrm{ng}$ of template DNA with either DreamTaq Green PCR Master Mix (Fermentas) or TaqMan Fast Advanced Master Mix (Fermentas), in a final volume of $10 \mu$ l. Each sample was run in duplicate, and samples were considered positive if the mean cycle threshold $\left(\mathrm{C}_{\mathrm{T}}\right)$ was $<35$, the delta between the two 
technical replicates was $<0.8$ cycles, and the curve was showing a clear exponential amplification. To estimate ' $\mathrm{Ca}$. L. solanacearum' titer in planta, we used the $\Delta \Delta \mathrm{C}_{\mathrm{T}}$ method whereby $\Delta \Delta \mathrm{C}_{\mathrm{T}}=$ $\Delta \mathrm{C}_{\mathrm{T}}$ (reference sample $)-\Delta \mathrm{C}_{\mathrm{T}}$ (target sample $)=\left(\mathrm{C}_{\mathrm{T}} \operatorname{Rec} \mathrm{A}-\mathrm{C}_{\mathrm{T}}\right.$ DcACTIN $)_{\text {healthy }}-\left(\mathrm{C}_{\mathrm{T}} \operatorname{Rec} \mathrm{A}-\Delta \mathrm{C}_{\mathrm{T}} \text { DcACTIN }\right)_{\text {inoculated. A healthy }}$ plant $C_{T}$ with the RecA primers was $\geq 35$, and $C_{T}$ mean with DcACTIN primers was 21; hence, the final equation was $\Delta \Delta \mathrm{C}_{\mathrm{T}}=$ $14-\left(\mathrm{C}_{\mathrm{T}} \operatorname{Rec} \mathrm{A}-\mathrm{C}_{\mathrm{T}} \text { DcACTIN }\right)_{\text {inoculated }}$.

Effect of carrot plant age on ' $\mathrm{Ca}$. L. solanacearum'induced shoot proliferation symptoms. To determine whether the physiological age of the plant affects the appearance of shoot proliferation symptoms, carrot seeds were sown in three different dates, with a 20- to 26-day difference, in a temperature-controlled chamber $\left(22\right.$ to $\left.25^{\circ} \mathrm{C}\right)$. For each date, six pots were sown with carrot seeds that were thinned after germination to three or four seedlings per pot. When the first sown plant age group had seven or eight true leaves, and the two other age groups had four or five and two or three true leaves, respectively; all three groups were inoculated with ' $\mathrm{Ca}$. L. solanacearum'-positive adults (IAP of 7 days), as described previously. Two pots (eight seedlings) were not inoculated, and they were used as negative controls. Symptom appearance (yes/no) was monitored for each plant starting 15 days after inoculation and continuing thereafter until all plants exhibited symptoms. The experiment was conducted twice, once in winter (October to February, day/night hours 10/14) and once in spring (March to June, day/night hours 13/11).

Effect of temperature on ' $\mathrm{Ca}$. L. solanacearum' titer in planta and on ' $\boldsymbol{C a}$. L. solanacearum'-induced shoot proliferation symptoms. Plants were grown at 22 to $25^{\circ} \mathrm{C}$ until 8 weeks after sowing (seven or eight true leaves) and then inoculated with
'Ca. L. solanacearum'-positive B. trigonica adults (IAP of $72 \mathrm{~h}$ ), as described previously. When the IAP was completed, psyllids were removed and plants were split between two adjacent chambers with different temperature settings. The high-temperature chamber was set to $30^{\circ} \mathrm{C}$ and the low-temperature chamber was set to $18^{\circ} \mathrm{C}$. Each temperature regime included 26 to 34 inoculated plants and 7 to 15 uninoculated control plants. Appearance of shoot proliferation symptom (yes/no) was monitored for each plant over time. Two similar experiments were conducted, the first in summer (May to September, day/night hours 14/10) and the second in winter (November to March, day/night hours 10/14). Temperature and relative humidity $(\mathrm{RH})$ in the growth chambers were recorded every 30 min with a HOBO Pro V2 data logger (Onset, MA). In the summer experiment the actual average temperature and $\mathrm{RH}$ in the two chambers were $18.2 \pm 0.5^{\circ} \mathrm{C}$ and $85 \% \pm 8$ and $30 \pm 1.8^{\circ} \mathrm{C}$ and $85 \% \pm 8$, respectively. In the winter experiment the actual average temperature and $\mathrm{RH}$ were $19.6 \pm 1.6^{\circ} \mathrm{C}$ and $76 \% \pm 15$ and $29.2 \pm$ $0.7^{\circ} \mathrm{C}$ and $56 \% \pm 1.8$.

In the first experiment, the incidence of ' $\mathrm{Ca}$. L. solanacearum' was estimated by qPCR at $10,18,26,31$, and 40 days postinoculation (dpi), with a composite sample of all plants from each pot, with four pots tested in each chamber. In the second experiment, both incidence and in planta titer of ' $\mathrm{Ca}$. L. solanacearum' were estimated. At each assessment point $(11,18,25,32,40$, and $60 \mathrm{dpi})$, a composite sample of one leaflet from the inoculated leaf of all plants in each pot was taken (six replicates for the first five timepoints and nine replicates for the final timepoint). Leaflets were always collected from the same inoculated leaf, moving from the lowest leaflet upward. Total DNA was extracted from each sample, and qPCR was used to determine ' $C a$. L. solanacearum' incidence and titer.
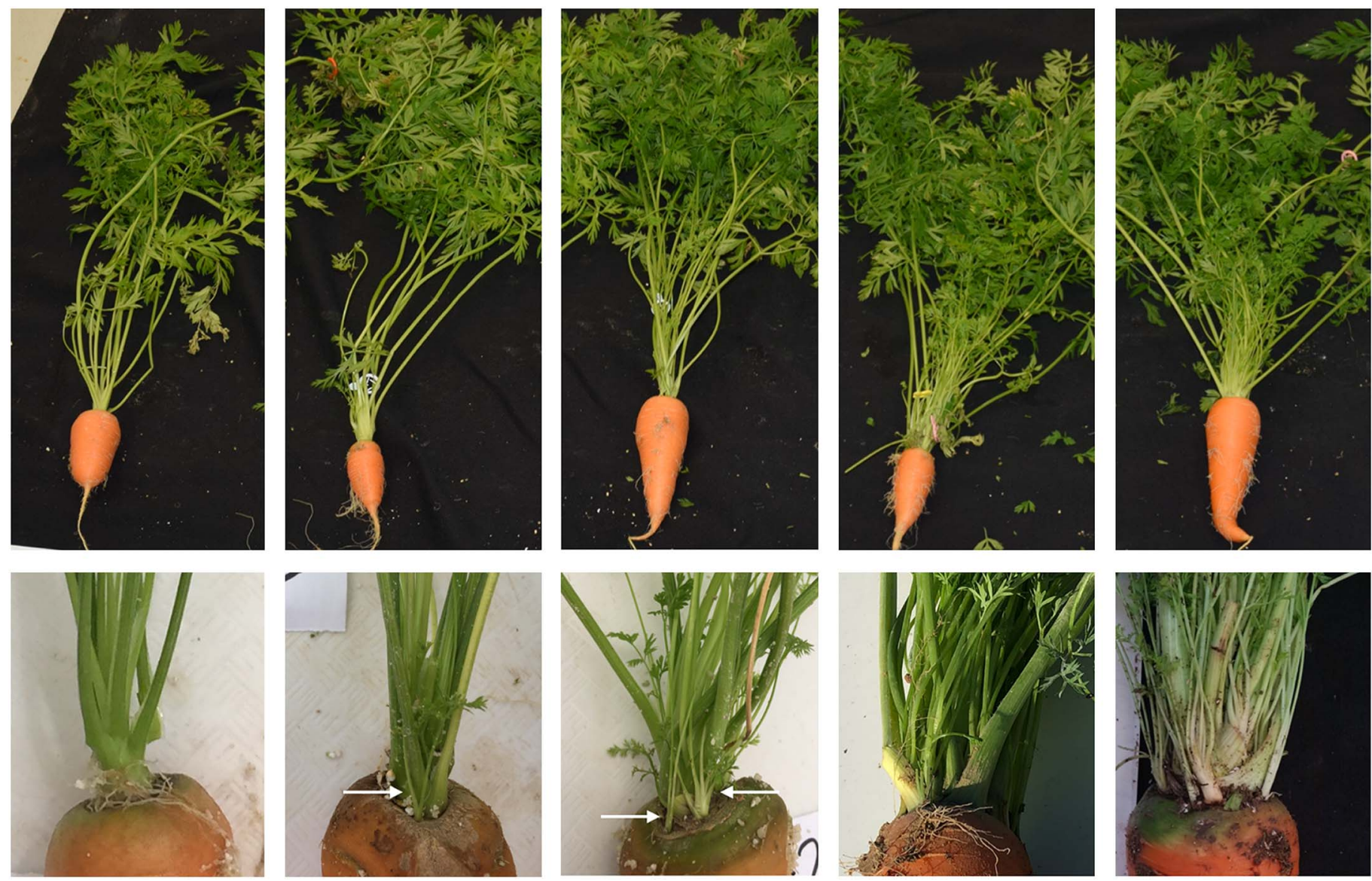

Fig. 1. Shoot proliferation symptoms induced by 'Candidatus Liberibacter solanacearum' haplotype D. Representative carrot plants infected with 'Ca. L. solanacearum' haplotype D showing shoot proliferation symptoms with increasing severity (from left to right). In both the top and the bottom panels, the image on the far left represents an uninfected, asymptomatic plant. The bottom panel shows an enlargement of the root crown section of symptomatic plants, where the proliferation of shoots is most visible. White arrows point to first new side shoots appearing in infected plants. 
Effect of vector load on 'Ca. L. solanacearum' titer in planta and on ' $\mathrm{Ca}$. L. solanacearum'-induced shoot proliferation symptoms. To determine the effect of vector load on ' $\mathrm{Ca}$. L. solanacearum' titer in planta and disease symptom development, carrot plants were individually inoculated with 2,10 , or 20 ' $\mathrm{Ca}$. L. solanacearum'positive $B$. trigonica adults, as described previously with $72 \mathrm{~h}$ IAP. Two experiments were conducted, the first in winter (September to December, day/night hours 11/13) and the second in spring and summer (April to July, day/night hours 13/11). Both experiments were conducted in the same chamber, in which the mean temperature and $\mathrm{RH}$ during the experiments were $22.3^{\circ} \mathrm{C} \pm 1.1$ and $77.3 \% \pm 12.4$ (first experiment) and $20.8^{\circ} \mathrm{C} \pm 0.7$ and $79.3 \% \pm 16.1$ (second experiment). For each inoculum load, 12 plants were inoculated and seven plants were left uninoculated as controls. Shoot proliferation symptom appearance (yes/no) was monitored for each plant over time. To evaluate ' $\mathrm{Ca}$. L. solanacearum' incidence and in planta titer, leaflets were collected from the inoculated leaf of 10 plants in each vector load group, moving from the lowest leaflet upward, at 10, 19, 31, 41, and 53 dpi. Leaflet samples were used for DNA extraction and qPCR.

Statistical analyses. Symptom appearance and ' $\mathrm{Ca}$. L. solanacearum' incidence in different treatments were analyzed via the Pearson $\chi^{2}$ test. For quantitative estimation of ' $C a$. L. solanacearum' titer, mean $\Delta \Delta \mathrm{C}_{\mathrm{T}}$ values of the groups were compared via one-way analysis of variance (ANOVA). When ANOVA assumptions were denied, Welch's test or the Wilcoxon matched-pairs signed-ranks test was used. To estimate the disease progress curve under different incubation temperatures or under different vector loads, data from both experiment replicates were pooled and a sigmoid plot was fitted. To examine the correlation between bacterial titer and disease symptoms, incidence data were pooled from both the temperature and vector load experiments, and an exponential plot was fitted. JMP software (SAS Institute Inc.) was used for all statistical analyses.

\section{RESULTS}

Effect of plant age on ' $\boldsymbol{C a}$. L. solanacearum'-induced shoot proliferation symptom. To test whether ' $C a$. L. solanacearum'associated shoot proliferation symptom appearance is delayed or inhibited in young carrot plants, we inoculated carrot plants at three different age groups and followed disease symptom appearance

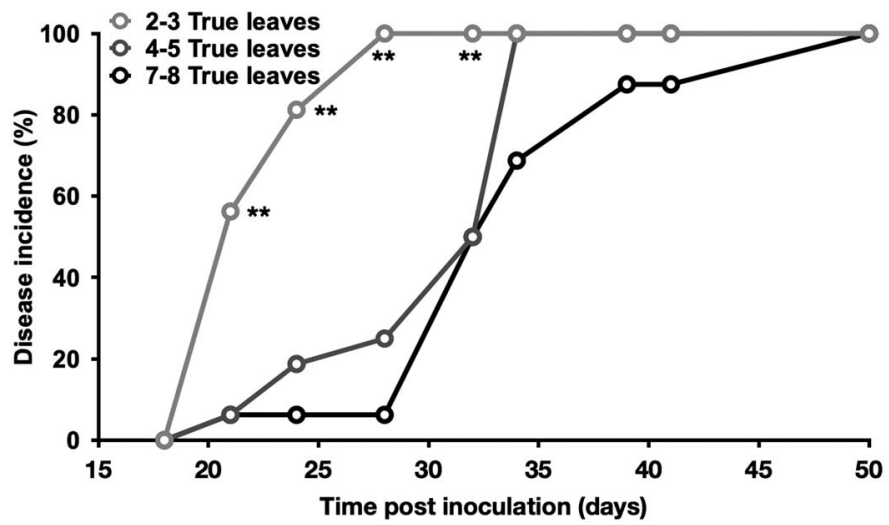

Fig. 2. 'Candidatus Liberibacter solanacearum'-induced shoot proliferation symptom appearance in carrot plants inoculated at different ages. Carrot plants at three different physiological ages (two or three true leaves, four or five true leaves, and seven or eight true leaves) were simultaneously inoculated with ' $\mathrm{Ca}$. L. solanacearum'-positive Bactericera trigonica adults, and shoot proliferation symptom appearance was monitored over time. Each group included six pots with four plants in each. The Pearson $\chi^{2}$ test was used to examine statistical differences at each timepoint. $* *$ Significant difference, $P<0.01$, between the group with two or three true leaves and the two older plant groups. No statistical differences were observed between the four or five and seven or eight true leaf groups at all timepoints. over time. In two independent experiments, plants of all ages showed typical shoot proliferation symptoms, with an incidence of nearly $100 \%$ at $40 \mathrm{dpi}$. In the first experiment there were no significant differences between the groups of plant ages at $28 \mathrm{dpi}\left(\chi^{2}=\right.$ 0.843 ; df $=2 ; P=0.656$ ), and at $35 \mathrm{dpi}$, all plants in all age groups were symptomatic (Supplementary Fig. S1). In the second experiment the number of symptomatic plants in the youngest group (two or three true leaves) was significantly higher at $21\left(\chi^{2}=15.1\right.$; $\mathrm{df}=$ $2 ; P=0.0005), 24\left(\chi^{2}=22.59 ; \mathrm{df}=2 ; P<0.0001\right), 28\left(\chi^{2}=32\right.$; $\mathrm{df}=2 ; P<0.0001)$, and $32\left(\chi^{2}=12 ; \mathrm{df}=2 ; P=0.0025\right) \mathrm{dpi}$ than the two older age groups (Fig. 2). Additionally, $100 \%$ of the plants in the youngest group developed symptoms within 28 days of inoculation, whereas 34 and 50 days were needed for the plants with four or five and seven or eight true leaves, respectively. Uninoculated control plants did not develop disease symptoms. These results indicate that carrot plants can display shoot proliferation symptoms when inoculated with ' $\mathrm{Ca}$. L. solanacearum' at both early and late physiological stages.

Effect of temperature on ' $\mathrm{Ca}$. L. solanacearum' growth in planta and on ' $\mathrm{Ca}$. L. solanacearum'-induced shoot proliferation symptoms. To test the effect of temperature on shoot proliferation symptom development and on ' $\mathrm{Ca}$. L. solanacearum' incidence and titer, carrot plants were inoculated with $B$. trigonica carrying ' $\mathrm{Ca}$. L. solanacearum' haplotype $\mathrm{D}$ and then moved into two adjacent chambers, one set at $18^{\circ} \mathrm{C}$ and the other at $30^{\circ} \mathrm{C}$. Two experiments were performed, the first in summer and the second in winter. The molecular incidence of ' $\mathrm{Ca}$. L. solanacearum' in the inoculated plants was tested in both experiments by qPCR and pooled for analysis. By $18 \mathrm{dpi}, 50 \%$ of tested plants in the $18^{\circ} \mathrm{C}$ chamber were positive for ' $\mathrm{Ca}$. L. solanacearum', whereas none were found in the $30^{\circ} \mathrm{C}$ chamber. At $40 \mathrm{dpi}, 100 \%$ of the tested plants in the $18^{\circ} \mathrm{C}$ were positive, compared with $20 \%$ in the $30^{\circ} \mathrm{C}$ chamber (Table 1). In accordance with the molecular incidence of ' $\mathrm{Ca}$. L. solanacearum', the bacterial titers were significantly higher in the $18^{\circ} \mathrm{C}$ than in the $30^{\circ} \mathrm{C}$ chamber, at all timepoints tested (excluding $10 \mathrm{dpi}$ ): at $18 \mathrm{dpi}$ (Welch's test, $F_{1,5.75}=18.9, P=$ 0.0053), 25 dpi (ANOVA, $F_{1,10}=38.8, P<0.0001$ ), $32 \mathrm{dpi}$ (Welch's test, $\left.F_{1,6.09}=44.1, P=0.0005\right), 42$ dpi (ANOVA, $F_{1,10}=$ $24.5, P=0.0006$ ), and 65 dpi (ANOVA, $F_{1,10}=4.56, P=0.047$ ) (Fig. 3). Additionally, ' $\mathrm{Ca}$. L. solanacearum' titers in plants incubated in the $30^{\circ} \mathrm{C}$ chamber remained statistically unchanged from 10 to 65 dpi (Welch's test, $F_{5,14.41}=0.962, P=0.472$ ), and in plants incubated in the $18^{\circ} \mathrm{C}$ chamber, titers were significantly higher than at the 10 dpi timepoint in all subsequent sampling points (Fig. 3).

In both experiments a significantly higher number of plants developed typical shoot proliferation symptoms in the $18^{\circ} \mathrm{C}$ chamber than in the $30^{\circ} \mathrm{C}$ chamber. In experiment $1,88 \%$ of the plants in the $18^{\circ} \mathrm{C}$ chamber showed typical disease symptoms $68 \mathrm{dpi}$ compared with only $29 \%$ in the $30^{\circ} \mathrm{C}$ chamber $\left(\chi^{2}=23.04\right.$; df $=1 ; P<$ $0.0001)$. In experiment $2,63 \%$ of the inoculated plants were symptomatic in the $18^{\circ} \mathrm{C}$ chamber at 50 dpi compared with only $23 \%$ in the $30^{\circ} \mathrm{C}$ chamber $\left(\chi^{2}=8.58\right.$; $\left.\mathrm{df}=1 ; P<0.0034\right)$ (Supplementary Fig. S2).

Experiments 1 and 2 did not differ significantly $\left(\chi^{2}=0.18\right.$; $\mathrm{df}=$ $1 ; P<0.6710)$ and therefore were pooled to generate disease

TABLE 1. Incidence of 'Candidatus Liberibacter solanacearum' in inoculated carrot plants grown at either 18 or $30^{\circ} \mathrm{C}$

\begin{tabular}{lcccr}
\hline Days postinoculation & $\begin{array}{c}18^{\circ} \mathrm{C} \\
\text { (positive/tested) }\end{array}$ & $\begin{array}{c}30^{\circ} \mathrm{C} \\
\text { (positive/tested) }\end{array}$ & $P^{\mathrm{a}}$ & $\chi^{2}$ \\
\hline 10 & $3 / 10$ & $0 / 10$ & 0.0603 & 3.53 \\
18 & $5 / 10$ & $0 / 10$ & 0.0098 & 6.66 \\
26 & $7 / 10$ & $1 / 10$ & 0.0062 & 7.50 \\
31 & $8 / 10$ & $1 / 9$ & 0.0044 & 8.10 \\
40 & $8 / 8$ & $2 / 10$ & 0.0007 & 11.52 \\
65 & $9 / 9$ & $4 / 9$ & 0.0274 & 4.86 \\
\hline
\end{tabular}

${ }^{\text {a }}$ Pearson $\chi^{2}$ test comparing the 18 and the $30^{\circ} \mathrm{C}$ chambers. 
progress curves; the sigmoid functions fitted to the data were highly significant $(P<0.0001)$, with $R^{2}$ values of 0.977 and 0.94 for the 18 and $30^{\circ} \mathrm{C}$ chambers, respectively (Fig. 4). Analysis of the sigmoid function describing the disease progress curve revealed that the main difference in disease development between the two temperatures tested is the asymptote (final number of symptomatic plants), estimated by the coefficient $a$ of the sigmoid curve. Coefficients $b$ and $X_{0}$ of the sigmoid curve, representing the slope (rate of symptom development), and the $50 \%$ infection point (number of days needed to reach $50 \%$ symptomatic plants), respectively, were comparable (Fig. 4B). Overall, these results suggest that a constant temperature of 29 to $30^{\circ} \mathrm{C}$ significantly inhibits ' $\mathrm{Ca}$. L. solanacearum' replication and infection and consequently lowers disease symptom appearance.

Effect of vector load on ' $\mathrm{Ca}$. L. solanacearum' growth in planta and on ' $\mathrm{Ca}$. L. solanacearum'-induced shoot proliferation symptoms. To test the association between ' $\mathrm{Ca}$. L. solanacearum' vector load, in planta titer, and symptom development, we inoculated individual carrot plants with 2,10 , or $20^{\circ} \mathrm{Ca}$. L. solanacearum'-positive $B$. trigonica adults, which were removed after an IAP of $72 \mathrm{~h}$. Two experiments were performed, the first in summer and the second in the winter. The number of ' $\mathrm{Ca}$. $\mathrm{L}$. solanacearum'-positive plants at the 10- and 20-psyllid loads was significantly higher than that of the two-psyllid load at the first two timepoints (10 and $19 \mathrm{dpi}$; Table 2). At later timepoints, ' $\mathrm{Ca}$. L. solanacearum' incidence did not differ significantly among treatments and reached $>80 \%$ in all treatments at $31 \mathrm{dpi}$. In planta estimations of ' $\mathrm{Ca}$. L. solanacearum' titer, measured from 10 to 53 dpi, were significantly higher in the 10- and 20-psyllid loads compared with the two-psyllid load inoculation in most sampling points, excluding the final timepoint 53 dpi (Fig. 5). No significant differences were found in ' $\mathrm{Ca}$. L. solanacearum' titers between plants inoculated with 10- or 20-psyllid loads at all timepoints tested.

In both experiments, disease symptoms were apparent earlier in plants inoculated with either 10 or 20 psyllids than in those inoculated with two psyllids (28.5 dpi \pm 3.4 compared with $36 \mathrm{dpi} \pm$ 4.8). However, this difference was not significant (ANOVA, $F_{1,10}$ $=1.6043, P=0.274)$. Nevertheless, plants inoculated with the

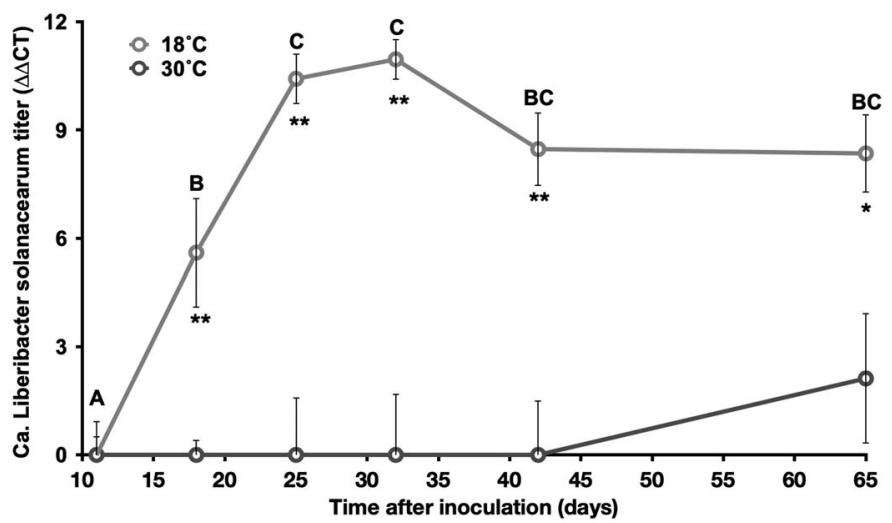

Fig. 3. The effect of growth temperature on 'Candidatus Liberibacter solanacearum' titers in planta. Carrot plants were inoculated with ' $\mathrm{Ca}$. L. solanacearum'-positive Bactericera trigonica adults and then placed in two adjacent chambers, one set at $18^{\circ} \mathrm{C}$ and the second at $30^{\circ} \mathrm{C}$. ' $\mathrm{Ca}$. L. solanacearum' titers were estimated at each timepoint by quantitative PCR and the $\Delta \Delta \mathrm{C}_{\mathrm{T}}$ method (six replicates per temperature for the first five timepoints and nine replicates for the sixth timepoint). Statistical differences between the two temperatures at each timepoint is marked with an asterisk $\left({ }^{*} P<\right.$ $\left.0.05,{ }^{*} P<0.01\right)$. Different timepoints (within each temperature) not sharing the same letter are significantly different $(P<0.05$, Wilcoxon matchedpairs signed-ranks test). No significant differences were found between timepoints in the $30^{\circ} \mathrm{C}$ chamber; therefore, letters are indicated only for the $18^{\circ} \mathrm{C}$ chamber. two-psyllid load were slower to reach $50 \%$ symptomatic plants compared with the 10- and 20-psyllid loads (46.5 dpi \pm 1.7 compared with 37.7 dpi \pm 1.2 ; ANOVA, $F_{1,4}=16.17, P=0.016$ ) (Supplementary Fig. S3). The percentage of symptomatic plants throughout the experiment was generally higher in the 10- and 20-psyllid load compared with the two-psyllid load and was statistically significant at multiple timepoints, as indicated in Supplementary Fig. S3. Differences in the percentage of symptomatic plants between the 10- and 20-psyllid loads were not significant in either experiment.

The two experiments conducted did not differ significantly $\left(\chi^{2}\right.$ $=0.41 ; \mathrm{df}=1 ; P<0.5205)$ and were therefore pooled to generate disease progress curves; the sigmoid functions fitted to the data were highly significant $(P<0.0001)$, with $R^{2}$ values of 0.915 , 0.958 , and 0.967 for the two-, 10-, and 20-psyllid treatments, respectively (Fig. 6). Analysis of the sigmoid function shows that the coefficient $X_{0}$, representing the $50 \%$ infection point, is the factor that differs the most between the two vector loads. Coefficients $a$ and $b$, representing the asymptote (final number of symptomatic plants) and the slope of the curve (rate of symptom development), respectively, were comparable between loads (Fig. 6B).

Assessing the correlation between ' $\mathrm{Ca}$. L. solanacearum' in planta titer and shoot proliferation symptoms. To assess the relationship between ' $\mathrm{Ca}$. L. solanacearum' titer and shoot proliferation symptoms, we pooled data from the temperature and vector load experiments (four independent experiments in total), where both bacterial titer and disease incidence were monitored over time. Data were used for regression analysis, and an exponential plot was found to best describe the relationship between ' $\mathrm{Ca}$. L. solanacearum' titer and symptoms, with an $R^{2}$ value of $0.835(P<0.0001)$ (Fig. 7). The graph illustrates that symptoms begin to appear only after a minimum threshold of ' $\mathrm{Ca}$. L. solanacearum' titer was obtained $\left(\Delta \Delta \mathrm{C}_{\mathrm{T}}\right.$ of about 5.9), and then disease incidence increases exponentially.

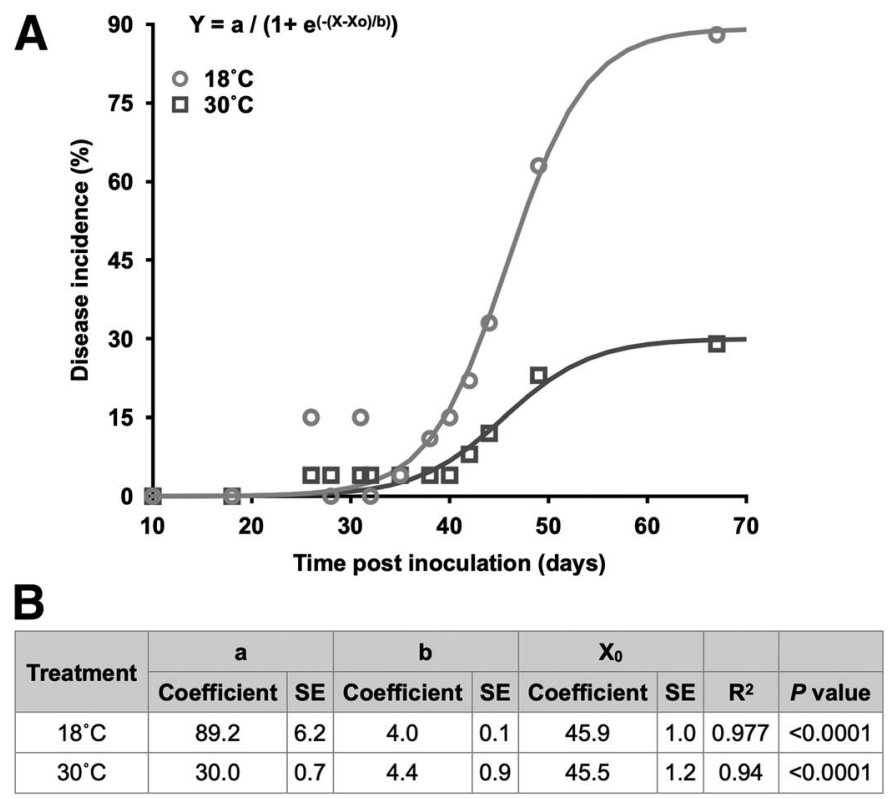

Fig. 4. The effect of growth temperature on 'Candidatus Liberibacter solanacearum'-induced shoot proliferation symptoms in carrot. Carrot plants were inoculated with ' $\mathrm{Ca}$. L. solanacearum'-positive Bactericera trigonica adults, and then split between two adjacent chambers with temperature set to either 18 or $30^{\circ} \mathrm{C}$. Appearance of shoot proliferation symptoms in each chamber was recorded over time. Each temperature included 26 to 34 plants. A, A sigmoid plot was fitted to data points pooled from two separate experiments. B, Details of the sigmoid plot equation parameters for each growth temperature. 


\section{DISCUSSION}

Despite the importance of ' $\mathrm{Ca}$. L. solanacearum', little is known about its interactions with Apiaceae host plants, insect vectors, and the effects of different environmental factors on the outcome of these interactions. Our results show that when carrot seedlings are infected with ' $\mathrm{Ca}$. L. solanacearum' haplotype D they develop typical shoot proliferation symptoms, similarly to (or faster than) older carrot plants (four or five and seven or eight true leaves). This finding led us to conclude that the early physiological stage of carrot seedlings does not pose a barrier in itself for symptom development and therefore cannot explain why carrot seedlings do not show symptoms in the field during the first months after sowing. Nevertheless, infection during different physiological stages may still have an important effect on plant productivity. For example, Rashed et al. (2014) showed that potato plants infested at an early stage by ' $C a$. L. solanacearum'-positive $B$. cockerelli had a significant reduction in tuber weight compared with plants infested at a later stage. Carrots showing shoot proliferation symptoms, on the other hand, had larger and heavier tap roots compared with asymptomatic carrots (Mawassi et al. 2018; Weintraub and Orenstein 2004); however, the physiological age at which the plants were inoculated was not determined.

The symptoms associated with ' $C a$. L. solanacearum' infection of carrots suggest that the disease agent interferes with the shoot/ root growth balance of plants, leading to abnormal growth (Mawassi et al. 2018; Nissinen et al. 2014; Weintraub and Orenstein 2004). We speculate that the physiological age at which plants are infected may determine how this imbalanced growth would be manifested. For example, if plants are infected at an early stage, tuber or taproot mass accumulation may be suppressed, but if infection occurs at later stages, taproot growth may be stimulated. However, this is speculative at this stage and must be experimentally tested.

In addition to plant age, we suspected that the lower temperatures of winter, in which many carrot fields in Israel are sown and grown, inhibit ' $\mathrm{Ca}$. L. solanacearum' growth and hence inhibit the appearance of disease symptoms. This suspicion is supported by controlled experiments done by Munyaneza et al. (2012a), showing that zebra chip symptoms (associated with haplotype $\mathrm{A} / \mathrm{B}$ ) were significantly delayed when plants were kept under a $17 / 12^{\circ} \mathrm{C}$ day/ night temperature regime. Nissinen et al. (2021), also suggested that the lower titers of ' $\mathrm{Ca}$. L. solanacearum' haplotype $\mathrm{C}$ observed in the second of a 2-year carrot field survey in Finland resulted from the cold summer temperatures that were recorded that year ( 1 to $2^{\circ} \mathrm{C}$ lower than the long-time average). In our experiments, a constant temperature of $18^{\circ} \mathrm{C}$ was shown to be conducive to disease development and in planta growth of ' $\mathrm{Ca}$. L. solanacearum', and hence $18^{\circ} \mathrm{C}$ is above the low temperature threshold needed to inhibit ' $C a$. L. solanacearum'. The long-term daily average winter (December to March) temperatures in regions where carrots are grown in Israel is significantly lower than $18^{\circ} \mathrm{C}\left(12\right.$ to $\left.14^{\circ} \mathrm{C}\right)$, and it is reasonable to speculate that these temperatures inhibit ' $\mathrm{Ca}$. $\mathrm{L}$. solanacearum' haplotype D. Unfortunately, the facility used in this study did not allow testing conditions that more accurately reflect Israel's winter temperatures, and the range of low temperatures that inhibit ' $C a$. L. solanacearum' haplotype $\mathrm{D}$ remains to be determined.

Munyaneza et al. (2012a) also showed that temperatures $>32^{\circ} \mathrm{C}$ were detrimental to ' $\mathrm{Ca}$. L. solanacearum' and completely prevented the appearance of disease symptoms. Data from HLB research also showed that ' $\mathrm{Ca}$. L. americanus' is heat sensitive and that temperatures $>32^{\circ} \mathrm{C}$ completely halted bacterial growth. The ' $\mathrm{Ca}$. L. asiaticus' strain, on the other hand, was not negatively affected even when incubation temperatures were $>35^{\circ} \mathrm{C}$ for a period of $5 \mathrm{~h}$ a day (Lopes et al. 2009). Because ' $C a$. L. solanacearum'-associated symptoms in Israel are most commonly seen in early summer (May to June), in which temperatures may rise to $\geq 30^{\circ} \mathrm{C}$ for several hours each day, we hypothesized that the local ' $\mathrm{Ca}$. L. solanacearum' isolate (haplotype D) is resilient to high temperatures. However, our experiments showed that when 'Ca. L. solanacearum'-inoculated carrot plants are incubated at a constant temperature of $30^{\circ} \mathrm{C}$, symptom appearance was significantly reduced. Our molecular tests also showed that infection itself was significantly inhibited at $30^{\circ} \mathrm{C}$, because even at the termination of the experiment, $>2$ months after inoculation, less than half of the plants tested positive for ' $C a$. L. solanacearum'. Estimation of ' $C a$. L. solanacearum' in planta titer throughout time further supported this notion, indicating that ' $\mathrm{Ca}$. L. solanacearum' infection was significantly inhibited at $30^{\circ} \mathrm{C}$. Additionally, it appears that the inhibition associated with high temperature was irrespective of day

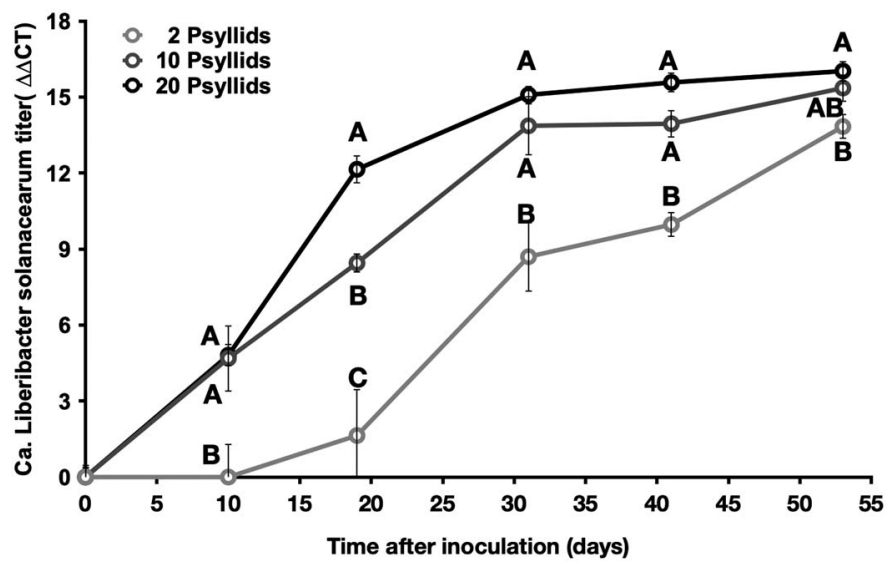

Fig. 5. The effect of vector load on 'Candidatus Liberibacter solanacearum' titers in planta. Carrot plants were individually inoculated with 2, 10, or 20 'Ca. L. solanacearum'-positive Bactericera trigonica adults for an inoculation access period of $72 \mathrm{~h}$, after which psyllids were eliminated and plants were grown at about $22^{\circ} \mathrm{C}$. We estimated 'Ca. L. solanacearum' titers at each timepoint by extracting total DNA from a single leaflet from each inoculated plant (10 plants per vector load) followed by quantitative PCR and the $\Delta \Delta \mathrm{C}_{\mathrm{T}}$ method. The Wilcoxon matched-pairs signed-ranks test was used to examine statistical differences between vector loads in each timepoint. Data points not sharing the same letter are statistically different.

TABLE 2. Incidence of 'Candidatus Liberibacter solanacearum' in carrot plants inoculated with 2, 10, or 20 psyllids per plant

\begin{tabular}{|c|c|c|c|c|c|}
\hline Days postinoculation & \multicolumn{3}{|c|}{ Number of psyllids per plant } & $P^{\mathrm{a}}$ & $\chi^{2}$ \\
\hline 19 & $3 / 10$ & $9 / 10$ & $10 / 10$ & 0.0007 & 18.26 \\
\hline 31 & $8 / 10$ & $10 / 10$ & $10 / 10$ & $N S^{b}$ & 4.28 \\
\hline 41 & $9 / 10$ & $10 / 10$ & $10 / 10$ & NS & 2.07 \\
\hline 53 & $10 / 10$ & $10 / 10$ & $10 / 10$ & NS & 0.0 \\
\hline
\end{tabular}

${ }^{\text {a }}$ Pearson $\chi^{2}$ test comparing the two-psyllid and the 10- or 20-psyllid groups.

${ }^{\mathrm{b}} \mathrm{NS}$, not significant. 
length and humidity, because in both experiments (which varied in day length and humidity) a similar trend of ' $\mathrm{Ca}$. L. solanacearum' inhibition was observed. These results cannot be attributed to lack of effective transmission, because the IAP was done at a conducive temperature, and only afterward were plants placed in the 18 and $30^{\circ} \mathrm{C}$ chambers. Interestingly, the inhibition effect of high temperatures on ' $\mathrm{Ca}$. L. solanacearum'-associated symptoms in an Apiaceae host was suggested by Teresani et al. (2014), based on celery field observations in 2008 to 2012, when a low incidence of ' $\mathrm{Ca}$. L. solanacearum' was associated with temperatures $>30^{\circ} \mathrm{C}$. Our experiments and results clearly support these observations.

Why are ' $\mathrm{Ca}$. L. solanacearum'-associated disease symptoms so common from May to July in Israel, when temperatures are well above $30^{\circ} \mathrm{C}$ during the day? One possible explanation is that daily temperature oscillations allow some relief and recovery for the bacterium and are therefore less detrimental than a constant temperature of $30^{\circ} \mathrm{C}$. Another possibility is that in spring, when temperatures are more favorable (March to April), ' $\mathrm{Ca}$. L. solanacearum' can effectively grow and establish in infected plants and that these high titers provide the bacterium with some degree of resistance to the negative effect of high temperatures in the months that follow (May to July). These speculations would have to be experimentally tested in controlled conditions to provide more specific answers. Understanding the range of inhibitory and conducive temperatures for ' $\mathrm{Ca}$. L. solanacearum' and for its psyllid vector would be crucial for making predictions about ' $\mathrm{Ca}$. L. solanacearum' damage based on environmental conditions and for our ability to wisely and successfully control the damage caused by this disease.

Our current inability to culture ' $\mathrm{Ca}$. L. solanacearum' in a pure axenic culture impedes the fulfillment of Koch's postulates. As a result, it is not possible at present to conclude that ' $\mathrm{Ca}$. L. solanacearum' is the sole responsible agent for the plant disorders with which it is associated. Despite this limitation, to strengthen the link between a suspected causal agent and disease symptoms, the following can be performed: testing a large sample size of symptomatic

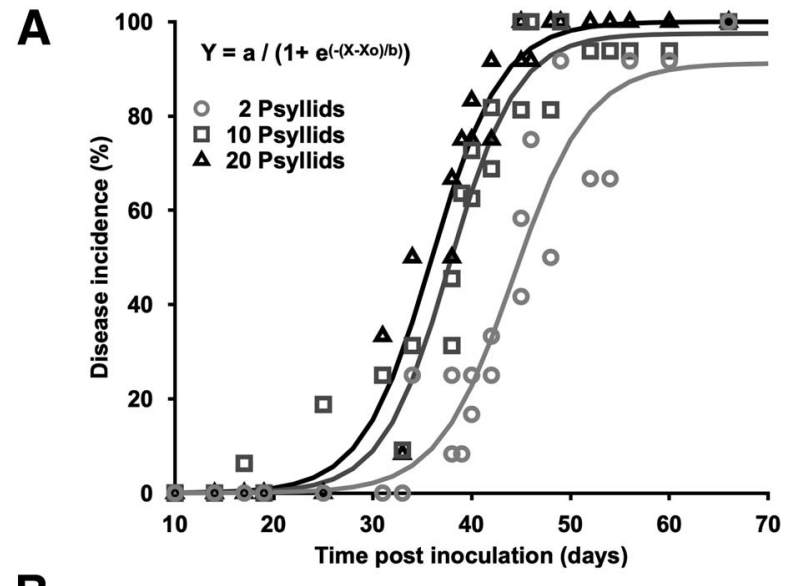

B

\begin{tabular}{|c|c|c|c|c|c|c|c|c|}
\hline $\begin{array}{c}\text { No.of } \\
\text { psyllids }\end{array}$ & \multicolumn{9}{|c|}{ a } & \multicolumn{4}{c|}{ b } & \multicolumn{2}{c|}{$\mathbf{X}_{0}$} & \\
\hline & Coefficient & SE & Coefficient & SE & Coefficient & SE & $R^{2}$ & P value \\
\hline 2 & 91.2 & 6.6 & 3.8 & 0.8 & 44.2 & 1.0 & 0.915 & $<0.0001$ \\
\hline 10 & 97.5 & 3.7 & 3.4 & 0.5 & 37.8 & 0.5 & 0.958 & $<0.0001$ \\
\hline 20 & 101.1 & 3.1 & 3.5 & 0.5 & 36.0 & 0.5 & 0.967 & $<0.0001$ \\
\hline
\end{tabular}

Fig. 6. The effect of vector load on 'Candidatus Liberibacter solanacearum'-induced shoot proliferation symptom in carrot. Carrot plants were individually inoculated with 2,10 , or 20 'Ca. L. solanacearum'-positive Bactericera trigonica adults for an inoculation access period of $72 \mathrm{~h}$. After inoculation, psyllids were eliminated and ' $\mathrm{Ca}$. L. solanacearum'-induced shoot proliferation symptom appearance was recorded over time. Each vector load included 12 plants. A, A sigmoid plot was fitted to data points pooled from two separate experiments. B, Details of the sigmoid plot equation parameters for each psyllid load. and asymptomatic plants for ' $\mathrm{Ca}$. L. solanacearum' presence and examining the association between symptoms and the presence of the suspected agent; conducting transmission assays when the insect vectors is available to provide further support; making microscopical observations of infected and uninfected plant material and associations with the suspected agent; and studying the relations between inoculum load, in planta titer of the suspect agent, and the rate of disease symptom appearance and severity. In a previous study we performed the first three, all supporting the notion that ' $\mathrm{Ca}$. L. solanacearum' is the responsible agent for the shoot proliferation symptoms seen in the field and in the greenhouse (Mawassi et al. 2018). In the current study, we assessed the correlation between vector load, in planta ' $\mathrm{Ca}$. L. solanacearum' titer, and development of disease symptoms over time.

Our results show that higher vector loads lead to faster symptom development. However, vector load did not affect the final number of symptomatic plants. This indicates that the main difference between the high and low vector loads is the time needed for ' $\mathrm{Ca}$. L. solanacearum' to reach the threshold after which symptoms appear. This was also evident from the regression analysis of ' $\mathrm{Ca}$. L. solanacearum' titer and disease incidence, which showed that only when ' $\mathrm{Ca}$. L. solanacearum' titer rose above a certain threshold did the disease incidence start to grow exponentially. These data provide further evidence to support the role of ' $\mathrm{Ca}$. L. solanacearum' as the main causal agent of these symptoms. The results are also in line with those of Rashed et al. (2012), who showed that zebra chip disease progress rate, after symptoms have started appearing, was independent of vector load. This finding can be explained by a lower number of ' $\mathrm{Ca}$. L. solanacearum' cells injected into the plant with the low vector load treatment, requiring more time to reach the cell threshold necessary for symptom development, but once this threshold was met, the disease progress rate was similar between the two vector loads.

Unfortunately, our inability to obtain and maintain a B. trigonica colony free of ' $\mathrm{Ca}$. L. solanacearum' did not allow us to conduct experiments by using a vector-only treatment to test the effects of psyllid feeding. As far as we know, the B. trigonica loads present in Israel carrot fields do not induce visible foliage symptoms.
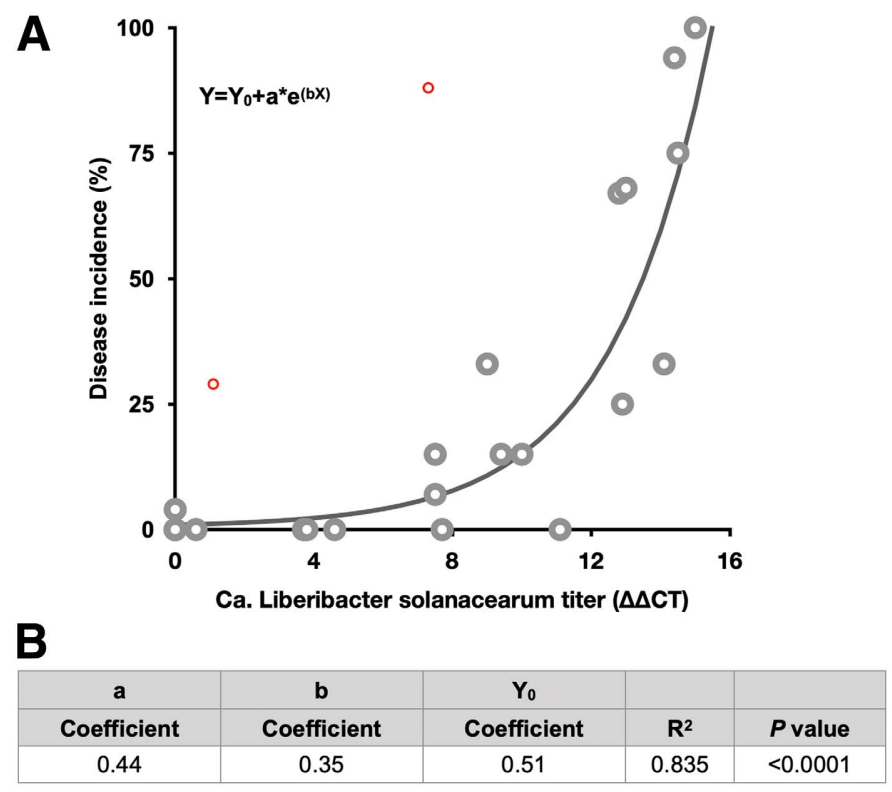

Fig. 7. Correlation between 'Candidatus Liberibacter solanacearum' titer and shoot proliferation symptoms. ' $\mathrm{Ca}$. L. solanacearum' titer and symptoms data were pooled from the temperature and vector load experiments (four independent experiments in total) and used for regression analysis. Two outlier points (out of 29 data points) were excluded from analysis (red circles). A, An exponential plot was fitted to the data. B, Details of the exponential plot equation parameters. 
Nevertheless, experiments with different loads of ' $\mathrm{Ca}$. L. solanacearum'-free vectors would be invaluable to examine the effect on carrot yield and to tease apart symptoms induced by vector feeding and those induced by the bacterium ' $\mathrm{Ca}$. L. solanacearum'.

In conclusion, the data presented here shed some light on the effect of temperature, plant age, and vector load on ' $\mathrm{Ca}$. L. solanacearum' haplotype D and associated symptoms in carrots. Despite the warm climate with which the distribution of ' $\mathrm{Ca}$. L. solanacearum' haplotype $\mathrm{D}$ is associated, it is dramatically influenced by temperature of $30^{\circ} \mathrm{C}$, inhibiting infection, in planta growth, and symptom development. A temperature of $18^{\circ} \mathrm{C}$, on the other hand, was found to be conducive to ' $\mathrm{Ca}$. L. solanacearum' growth and symptom development. We further showed that carrot seedlings could develop shoot proliferation symptoms when inoculated under favorable conditions, although they do not show symptoms under field conditions. It is likely that a combination of factors such as low inoculum load (vectors colonized by ' $\mathrm{Ca}$. L. solanacearum') and temperatures that go below $18^{\circ} \mathrm{C}$ long enough are responsible for the scarcity of symptoms in young carrot seedlings in the field. Finally, experiments with vector load and in planta monitoring of ' $C a$. L. solanacearum' titers strengthen the link between this fastidious and yet-unculturable bacterium with shoot proliferation symptoms in carrots, strongly supporting the notion that it is the main responsible agent for these disease symptoms.

\section{ACKNOWLEDGMENTS}

We thank Dani Shtienberg for his assistance with statistical analyses, and Mark Krisa and Adiso Zalaka for their valuable technical assistance during this study.

\section{LITERATURE CITED}

Alfaro-Fernández, A., Cebrian, M. C., Villaescusa, F. J., de Mendoza, A. H., Ferrándiz, J. C., Sanjuán, S., and Font, M. I. 2012a. First report of "Candidatus Liberibacter solanacearum" in carrot in mainland Spain. Plant Dis. 96:582.

Alfaro-Fernández, A., Hernández-Llópis, D., Ibáñez, I., Rodríguez-León, F., Ferrándiz, J. C., Sanjuán, S., and Font, M. I. 2015. First report of Spiroplasma citri in celery in Spain. Plant Dis. 99:1175.

Alfaro-Fernández, A., Siverio, F., Cebrián, M. C., Villaescusa, F. J., and Font, M. I. 2012b. "Candidatus Liberibacter solanacearum" associated with Bactericera trigonica-affected carrots in the Canary Islands. Plant Dis. 96:581-582.

Antolínez, C. A., Fereres, A., and Moreno, A. 2017. Sex-specific probing behaviour of the carrot psyllid Bactericera trigonica and its implication in the transmission of 'Candidatus Liberibacter solanacearum'. Eur. J. Plant Pathol. 147:627-637.

Ben Othmen, S., Morán, F. E., Navarro, I., Barbé, S., Martínez, C., MarcoNoales, E., Chermiti, B., and López, M. M. 2018. 'Candidatus Liberibacter solanacearum' haplotypes $\mathrm{D}$ and $\mathrm{E}$ in carrot plants and seeds in Tunisia. J. Plant Pathol. 100:197-207.

Bové, J. M. 2006. Huanglongbing: A destructive, newly-emerging, centuryold disease of citrus. J. Plant Pathol. 88:7-37.

Buchman, J. L., Heilman, B. E., and Munyaneza, J. E. 2011. Effects of Liberibacter-infective Bactericera cockerelli (Hemiptera: Triozidae) density on zebra chip potato disease incidence, potato yield, and tuber processing quality. J. Econ. Entomol. 104:1783-1792.

Chang, R. J., Ries, S. M., and Pataky, J. K. 1992. Effects of temperature, plant age, inoculum concentration, and cultivar on the incubation period and severity of bacterial canker of tomato. Plant Dis. 76:1150-1155.

Haapalainen, M., Kivimäki, P., Latvala, S., Rastas, M., Hannukkala, A., Jauhiainen, L., Lemmetty, A., Pirhonen, M., Virtanen, A., and Nissinen, A. 2016. Frequency and occurrence of the carrot pathogen "Candidatus Liberibacter solanacearum" haplotype C in Finland. Plant Pathol. 66:559-570.

Haapalainen, M., Latvala, S., Wickström, A., Wang, J., Pirhonen, M., and Nissinen, A. I. 2019. A novel haplotype of 'Candidatus Liberibacter solanacearum' found in Apiaceae and Polygonaceae family plants. Eur. J. Plant Pathol. 156:413-423.

Haapalainen, M., Wang, J., Latvala, S., Lehtonen, M. T., Pirhonen, M., and Nissinen, A. I. 2018. Genetic variation of 'Candidatus Liberibacter solanacearum' haplotype $\mathrm{C}$ and identification of a novel haplotype from Trioza urticae and stinging nettle. Phytopathology 108:925-934.
Hajri, A., Loiseau, M., Cousseau-Suhard, P., Renaudin, I., and Gentit, P. 2017. Genetic characterization of 'Candidatus Liberibacter solanacearum' haplotypes associated with apiaceous crops in France. Plant Dis. 101:1383-1390.

Hansen, A. K., Trumble, J. T., Stouthamer, R., and Paine, T. D. 2008. A new huanglongbing species, "Candidatus Liberibacter psyllaurous," found to infect tomato and potato, is vectored by the psyllid Bactericera cockerelli (Sulc). Appl. Environ. Microbiol. 74:5862-5865.

Ibanez, F., Levy, J., and Tamborindeguy, C. 2014. Transcriptome analysis of "Candidatus Liberibacter solanacearum" in its psyllid vector, Bactericera cockerelli. PLoS One 9:e100955.

Kus, J. V., Zaton, K., Sarkar, R., and Cameron, R. K. 2002. Age-related resistance in Arabidopsis is a developmentally regulated defense response to Pseudomonas syringae. Plant Cell 14:479-490.

Li, W., Abad, J. A., French-Monar, R. D., Rascoe, J., Wen, A., Gudmestad, N. C., Secor, G. A., Lee, I.-M., Duan, Y., and Levy, L. 2009. Multiplex real-time PCR for detection, identification and quantification of "Candidatus Liberibacter solanacearum" in potato plants with zebra chip. J. Microbiol. Methods 78:59-65.

Li, W., Hartung, J. S., and Levy, L. 2006. Quantitative real-time PCR for detection and identification of Candidatus Liberibacter species associated with citrus huanglongbing. J. Microbiol. Methods 66:104-115.

Liefting, L. W., Perez-Egusquiza, Z. C., and Clover, G. R. G. 2008. A new 'Candidatus Liberibacter' species in Solanum tuberosum in New Zealand. Plant Dis. 92:1474.

Loiseau, M., Garnier, S., Boirin, V., Merieau, M., Leguay, A., Renaudin, I., Renvoisé, J.-P., and Gentit, P. 2014. First report of 'Candidatus Liberibacter solanacearum' in carrot in France. Plant Dis. 98:839.

Lopes, S. A., Frare, G. F., Bertolini, E., Cambra, M., Fernandes, N. G., Ayres, A. J., Marin, D. R., and Bové, J. M. 2009. Liberibacters associated with citrus huanglongbing in Brazil: 'Candidatus Liberibacter asiaticus' is heat tolerant, 'Ca. L. americanus' is heat sensitive. Plant Dis. 93:257-262.

Mauck, K. E., Sun, P., Meduri, V., and Hansen, A. K. 2019. New Ca. Liberibacter psyllaurous haplotype resurrected from a 49-year-old specimen of Solanum umbelliferum: A native host of the psyllid vector [published correction appears in Sci. Rep. 9:17726]. Sci. Rep. 9:9530.

Mawassi, M., Dror, O., Bar-Joseph, M., Piasetzky, A., Sjölund, J., Levitzky, N., Shoshana, N., Meslenin, L., Haviv, S., Porat, C., Katsir, L., Svetlana, K., Ghanim, M., Zelinge-Reichert, E., Arnsdorf, M. Y., Gera, A., and Bahar, O. 2018. 'Candidatus Liberibacter solanacearum' is tightly associated with carrot yellows symptoms in Israel and transmitted by the prevalent psyllid vector Bactericera trigonica. Phytopathology 108:10561066.

Munyaneza, J. E., Crosslin, J. M., and Upton, J. E. 2007. Association of Bactericera cockerelli (Homoptera: Psyllidae) with "zebra chip," a new potato disease in southwestern United States and Mexico. J. Econ. Entomol. 100:656-663.

Munyaneza, J. E., Fisher, T. W., Nissinen, A., Sengoda, V. G., Lemmetty, A., and Garczynski, S. F. 2010. First report of "Candidatus Liberibacter solanacearum" associated with psyllid-affected carrots in Europe. Plant Dis. 94:639.

Munyaneza, J. E., Sengoda, V. G., Buchman, J. L., and Fisher, T. W. 2012a. Effects of temperature on "Candidatus Liberibacter solanacearum" and zebra chip potato disease symptom development. Plant Dis. 96:18-23.

Munyaneza, J. E., Sengoda, V. G., Stegmark, R., Arvidsson, A. K., Anderbrant, O., Yuvaraj, J. K., Rämert, B., and Nissinen, A. 2012b. First report of "Candidatus Liberibacter solanacearum" associated with psyllidaffected carrots in Sweden. Plant Dis. 96:453.

Munyaneza, J. E., Sengoda, V. G., Sundheim, L., Meadow, R., and America, C. 2014. Survey of "Candidatus Liberibacter solanacearum" in carrot crops affected by the psyllid Trioza apicalis (Hemiptera: Triozidae) in Norway. J. Plant Pathol. 96:397-402.

Munyaneza, J. E., Swisher, K. D., Hommes, M., Willhauck, A., Buck, H., and Meadow, R. 2015. First report of 'Candidatus Liberibacter solanacearum' associated with psyllid-infested carrots in Germany. Plant Dis. 99: 1269.

Nelson, W., Sengoda, V., Alfaro-Fernández, A. O., Font, M. I., Crosslin, J. M., and Munyaneza, J. E. 2013a. A new haplotype of "Candidatus Liberibacter solanacearum" identified in the Mediterranean region. Eur. J. Plant Pathol. 135:633-639.

Nelson, W. R., Fisher, T. W., and Munyaneza, J. E. 2011. Haplotypes of "Candidatus Liberibacter solanacearum" suggest long-standing separation. Eur. J. Plant Pathol. 130:5-12.

Nelson, W. R., Munyaneza, J. E., Mccue, K. F., and Bové, J. M. 2013b. The pangaean origin of "Candidatus liberibacter" species. J. Plant Pathol. 95: 455-461.

Nissinen, A. I., Haapalainen, M., Jauhiainen, L., Lindman, M., and Pirhonen, M. 2014. Different symptoms in carrots caused by male and female carrot psyllid feeding and infection by 'Candidatus Liberibacter solanacearum'. Plant Pathol. 63:812-820. 
Nissinen, A. I., Haapalainen, M., Ojanen, H., Pirhonen, M., and Jauhiainen, L. 2021. Spreading of Trioza apicalis and development of "Candidatus Liberibacter solanacearum" infection on carrot in the field conditions. Ann. Appl. Biol. 178:39-50.

Orenstein, S., Franck, A., Kuznetzova, L., Sela, I., and Tanne, E. 1999. Association of phytoplasmas with a yellows disease of carrot in Israel. J. Plant Pathol. 81:193-199.

Rashed, A., Nash, T. D., Paetzold, L., Workneh, F., and Rush, C. M. 2012. Transmission efficiency of "Candidatus Liberibacter solanacearum" and potato zebra chip disease progress in relation to pathogen titer, vector numbers, and feeding sites. Phytopathology 102:1079-1085.

Rashed, A., Workneh, F., Paetzold, L., Gray, J., and Rush, C. M. 2014. Zebra chip disease development in relation to plant age and time of "Candidatus liberibacter solanacearum" infection. Plant Dis. 98:24-31.

Swisher Grimm, K. D., and Garczynski, S. F. 2019. Identification of a new haplotype of 'Candidatus Liberibacter solanacearum' in Solanum tuberosum. Plant Dis. 103:468-474.

Tahzima, R., Maes, M., Achbani, E. H., Swisher, K. D., Munyaneza, J. E., and De Jonghe, K. 2014. First report of 'Candidatus Liberibacter solanacearum' on carrot in Africa. Plant Dis. 98:1426.
Tahzima, R., Massart, S., Achbani, E. H., Munyaneza, J. E., and Ouvrard, D. 2017. First report of 'Candidatus Liberibacter solanacearum' associated with the psyllid Bactericera trigonica Hodkinson on carrots in northern Africa. Plant Dis. 101:242.

Teresani, G. R., Bertolini, E., Alfaro-Fernández, A., Martínez, C., Tanaka, F. A. O., Kitajima, E., Roselló, M., Sanjuán, S., Ferrándiz, J. C., López, M. M., Cambra, M., and Font, M. I. 2014. Association of "Candidatus Liberibacter solanacearum" with a vegetative disorder of celery in Spain and development of a real-time PCR method for its detection. Phytopathology 104:804-811.

Teresani, G. R., Hernández, E., Bertolini, E., Siverio, F., Moreno, A., Fereres, A., and Cambra, M. 2017. Transmission of 'Candidatus Liberibacter solanacearum' by Bactericera trigonica Hodkinson to vegetable hosts. Span. J. Agric. Res. 15:e1011.

Tian, C., Jiang, Q., Wang, F., Wang, G. L., Xu, Z. S., and Xiong, A. S. 2015. Selection of suitable reference genes for qPCR normalization under abiotic stresses and hormone stimuli in carrot leaves. PLoS One 10:e0117569.

Weintraub, P., and Orenstein, S. 2004. Potential leafhopper vectors of phytoplasma in carrots. Int. J. Trop. Insect Sci. 24:228-235. 